ORIGINAL ARTICLE

\title{
Microvessel density and clinicopathological characteristics in hepatitis $C$ virus and hepatitis $B$ virus related hepatocellular carcinoma
}

\author{
L Messerini, L Novelli, C E Comin
}

J Clin Pathol 2004;57:867-871. doi: 10.1136/icp.2003.015784

See end of article for authors' affiliations ......................

Correspondence to: Professor C E Comin, Department of Human Pathology and Oncology, University of Florence Medical School, Viale G.B. Morgagni, 85, 50134 Firenze, Italia; camilla. comin@unifi.it

Accepted for publication 24 March 2004
Aims: To compare intratumorous microvessel density (MVD) and clinicopathological features in two different groups of hepatocellular carcinoma $(\mathrm{HCC})$, namely: hepatitis B virus (HBV) related HCC (B-HCC) and HCV related HCC (C-HCC).

Methods: Fifty consecutive cases each of B-HCC and of C-HCC were studied. Microvessel numbers were assessed by staining for the antigen CD34; in each case, three areas with the highest numbers of microvessels were counted in both the intratumorous and the surrounding non-tumorous tissue; the mean value represented the final MVD.

Results: Patients with B-HCC were significantly younger than those with C-HCC (mean age, 60.1 (SD, 4.1) $\checkmark 66.4$ (4.3) years); no significant differences were seen for sex or Child's class distribution. The tumour diameter was larger in B-HCCs than in C-HCCs (mean, 5.6 (SD, 1.8) v $3.8(1.8) \mathrm{cm}$ ). Tumour microsatellite formation was significantly higher in C-HCCs (12 14 cases). No differences were found for histological subtype, degree of differentiation, tumour encapsulation, and vascular invasion. The mean MVD value was significantly higher in tumorous (mean, 54 (SD, 13.8) $v 38$ (8.9)) and in the surrounding non-tumorous liver tissue (mean, 15 (SD, 4.3) v 7 (3.1)) of C-HCCs.

Conclusions: C-HCCs present as smaller tumours in older patients, with a higher incidence of tumour microsatellite formation and higher MVD values both in the tumorous and the non-tumorous areas, suggesting a link between HCV infection, angiogenesis, and hepatocarcinogenesis.
C hronic hepatitis $\mathrm{B}$ and $\mathrm{C}$ are thought to be the major causes of cirrhosis and of hepatocellular carcinoma (HCC). Hepatitis B virus (HBV) related hepatocarcinogenesis has been studied intensively and largely clarified during the past decade ${ }^{1-3}$ but the carcinogenetic mechanism of hepatitis C virus (HCV) still remains unclear. ${ }^{4-5}$ Furthermore, the clinicopathological features of resected HCC with HBV and HCV infections can differ, ${ }^{6-17}$ thus suggesting different mechanisms of carcinogenesis for these two viruses.

\section{"The carcinogenetic mechanism of hepatitis C virus still} remains unclear"

Angiogenesis is of crucial importance to tumour growth and the metastasis of solid tumours. ${ }^{18} 19$ The importance of angiogenesis for tumour growth is supported by the observation that an avascular tumour rarely grows larger than $2-3 \mathrm{~mm}^{2}$, but once a tumour becomes vascularised, tumour growth is rapid. ${ }^{20}{ }^{21}$ HCC is a hypervascular tumour, but unlike other solid tumours an inverse correlation between angiogenesis and tumour size has been found. ${ }^{22-24}$ The importance of neovascularisation in the progression of HCC has been highlighted in recent studies, ${ }^{25}{ }^{26}$ which showed that microvessels increase gradually from cirrhotic nodules through low grade and high grade dysplastic nodules, with the greatest numbers recorded in HCC. To date, few reports have compared microvessel density (MVD) in HBV and HCV associated HCC, and they have found no differences.22 2728 However, non-neoplastic livers infected with HCV showed a higher MVD than those infected with $\mathrm{HBV},{ }^{28}{ }^{29}$ and a possible active role for HCV in angiogenesis has been suggested. ${ }^{28-30}$
To clarify these apparently conflicting data we evaluated angiogenesis, as measured by microvessel counting, in two different groups of HCC, namely: HBV related (B-HCC) and HCV related HCCs (C-HCC) and in the surrounding liver tissue. We also carried out a comparative study of the clinicopathological features of both groups of tumours.

\section{MATERIAL AND METHODS \\ Case selection}

Between January 1997 and December 2002, 219 surgically resected HCCs were collected in the department of human pathology and oncology at the University of Florence, Italy. For the purposes of the study we selected 50 consecutive cases of B-HCC and C-HCC that met the following criteria: (1) cirrhosis Child's class A or B; (2) hepatic resection was considered curative; (3) the tumours presented as single nodular lesions; (4) no other treatments for HCC; (5) no apparent distant metastases. Complete preoperative serological tests were available for each case. HBV infection was confirmed by the detection of the HBV surface antigen and HBV core antigen; HCV infection was established using commercial enzyme linked immunosorbant assays for antiHCV antibodies. Patients with evidence of co-infection were excluded from our study, as were those with an associated history of alcohol abuse. In all cases, multiple sections of the tumour and the surrounding tissue were available.

Abbreviations: B-HCC, hepatitis B virus hepatocellular carcinoma; C$\mathrm{HCC}$, hepatitis $C$ virus related hepatocellular carcinoma; COX-2, cyclooxygenase-2; HBV, hepatitis B virus; HCC, hepatocellular carcinoma; $\mathrm{HCV}$, hepatitis $\mathrm{C}$ virus; $\mathrm{iNOS}$, inducible nitric oxide synthase; MVD, microvessel density; PD-ECGF, platelet derived endothelial cell growth factor 


\section{Pathological examination}

The morphological and histological features of all cases were reviewed. An adequate number of sections from each tumour (six on average; range, 4-12 sections depending on tumour diameter) and surrounding tissue were available for our study. Tumour size was measured as the maximal diameter of the tumour by gross examination. The presence of a tumour capsule, evidence of vascular invasion, and tumour microsatellite formation were assessed by microscopic examination. Smaller neoplastic nodules clearly separated from the main lesion were considered to be tumour microsatellite nodules. Microsatellite formations were divided into multifocal and metastatic groups. Multifocal HCC was defined according to the histological criteria of Tsuda et al. ${ }^{31}$ Satellite nodules consisting of Edmondson's grade II, III, or IV HCCs and exhibiting a similar or lower grade of differentiation in comparison with the main tumour were categorised as intrahepatic metastases. ${ }^{32}$

Tumours were histologically subtyped according to the World Health Organisation classification system. ${ }^{33}$ The degree of differentiation was determined according to Edmondson and Steiner, ${ }^{34}$ and was stratified into those tumours with better (Edmondson grade I and II) and poorer (Edmondson grade III and IV) cellular differentiation.

\section{Immunohistochemistry}

Immunohistochemical staining was performed for CD34 on $4 \mu \mathrm{m}$ thick, formalin fixed, paraffin wax embedded sections, using the streptavidin-biotin immunoperoxidase technique. A monoclonal anti-CD34 antibody (Immunotech, Marsiglia, France) was used at a $1 / 100$ dilution. Antigen retrieval consisted of microwave treatment with citrate buffer, $\mathrm{pH}$ 6.0, for 10 minutes. As a negative control for each case, the primary antibody was replaced with normal rabbit serum. We chose CD34 because it is more sensitive than other markers for liver endothelial cells. ${ }^{24} 2728$ 35-37

\section{Evaluation of MVD}

MVD was assessed by light microscopy using the counting method introduced by Weidner et al..$^{38}$ CD34 was used to identify and count intratumorous and extratumorous vessels. Tumorous and non-tumorous tissue sections were scanned at low magnification $(\times 40$ and $\times 100)$ to find the areas that showed the most intense vascularisation (hot spots). Individual microvessels were counted in three fields at $\times 200$ magnification $(\times 20$ objective lens and $\times 10$ ocular lens; $0.7386 \mathrm{~mm}^{2}$ /field). The final MVD was the mean value obtained from the counts of the three fields. MVD was expressed as mean (SD) (vessels $/ \mathrm{mm}^{2}$ ). Any immunostained endothelial cells or endothelial cell clusters that were clearly separated from the adjacent microvessels, tumour cells, and other connective tissue elements were considered to be single and countable microvessels. Vessel lumens were not necessary for a structure to be defined as a microvessel, and red blood cells were not used to define a vessel lumen. ${ }^{38}$ The evaluation of MVD was performed without knowledge of the clinicopathological data.

Table 1 Comparison of clinical data between B-HCC and C-HCC

\begin{tabular}{llll}
\hline Variable & B-HCC & C-HCC & p Value \\
\hline Mean (SD) age in years & $60.1(4.1)$ & $66.4(4.3)$ & $<0.001$ \\
Sex (M/F) & $40 / 10$ & $42 / 8$ & NS \\
Child's class (A/B) & $34 / 16$ & $31 / 19$ & NS \\
\hline
\end{tabular}

B-HCC, hepatitis B virus related hepatocellular carcinoma; C-HCC, hepatitis $C$ virus related hepatocellular carcinoma; NS, not significant.

\section{Statistical analysis}

Statistical analysis was performed using the SPSS software program (version 9.0 for Windows; SPSS Inc, Chicago, Illinois, USA). The Wilcoxon test and $\chi^{2}$ test were used to compare the findings between the two groups (B-HCC and $\mathrm{C}$-HCC). Tests were considered significant when their $\mathrm{p}$ values were less than 0.05 .

\section{RESULTS}

\section{Clinicopathological features}

Table 1 shows the distribution of the clinical data in our study population. The patients with B-HCC (mean age, 60.1; $\mathrm{SD}, 4.1$ years) were significantly younger than those with C-HCC (mean, 66.4; SD, 4.3) $(\mathrm{p}<0.001)$. No significant differences were found with regard to sex and Child's class distribution. Among the tumour related factors, the tumour diameter of the B-HCC group (mean, 5.6; SD, $1.8 \mathrm{~cm}$ ) was significantly greater than that found in C-HCC (mean, 3.8; $\mathrm{SD}, 1.8 \mathrm{~cm})(\mathrm{p}<0.001)$. Tumours larger than $5 \mathrm{~cm}$ were found more frequently in the B-HCC group; no differences were found for small or moderate sized tumours, although a trend towards a higher number of tumours $\leqslant 2 \mathrm{~cm}$ was seen in the C-HCC group (table 2). Tumour microsatellite formation was seen significantly more often in the C-HCC group ( 12 cases) than in the B-HCC group (four cases) $(p=0.03)$. Multifocal HCC was found in nine of the 12 C-HCC cases and in one of the four B-HCC cases with tumour satellite nodules; these differences were significant $(\mathrm{p}<$ 0.007). Three patients showed intrahepatic metastases in both groups; differences were not significant $(\mathrm{p}=0.67)$.

No significant differences between the two groups were found when evaluating histological subtype, cellular differentiation, tumour encapsulation, and vascular invasion (table 2).

\section{Microvessel density}

Microvessels were found to be heterogeneously distributed within the tumour, and maximal density was seen at the periphery of the lesion, near the borders (fig 1). The mean value of tumour MVD was 47 (SD, 11.4; range, 18-78). When MVD was correlated with clinicopathological features, significantly higher MVD values were associated with

\begin{tabular}{|c|c|c|c|}
\hline Variable & $\begin{array}{l}\text { B-HCC } \\
N\end{array}$ & $\begin{array}{l}\mathrm{C}-\mathrm{HCC} \\
\mathrm{N}\end{array}$ & p Value \\
\hline \multicolumn{4}{|l|}{ Tumour size } \\
\hline$\leqslant 2 \mathrm{~cm}$ & 2 & 6 & NS \\
\hline $2.1-5 \mathrm{~cm}$ & 30 & 37 & NS \\
\hline$>5 \mathrm{~cm}$ & 18 & 7 & 0.01 \\
\hline \multicolumn{4}{|l|}{ Architectural pattern } \\
\hline Trabecular & 36 & 35 & NS \\
\hline Pseudoglandular & 10 & 9 & \\
\hline Compact & 3 & 5 & \\
\hline Clear cell & 1 & 1 & \\
\hline \multicolumn{4}{|l|}{ Edmondson grade } \\
\hline $\mathrm{G} 1-\mathrm{G} 2$ & 29 & 27 & NS \\
\hline G3-G4 & 21 & 23 & \\
\hline \multicolumn{4}{|c|}{ Microsatellite formation } \\
\hline Absent & 46 & 38 & 0.03 \\
\hline Present & 4 & 12 & \\
\hline \multicolumn{4}{|l|}{ Fibrous capsule } \\
\hline Absent & 45 & 43 & NS \\
\hline Present & 5 & 7 & \\
\hline \multicolumn{4}{|l|}{ Vessel involvement } \\
\hline Absent & & & NS \\
\hline Present & 17 & 15 & \\
\hline
\end{tabular}

B-HCC, hepatitis B virus related hepatocellular carcinoma; C-HCC, hepatitis $C$ virus related hepatocellular carcinoma; NS, not significant. 


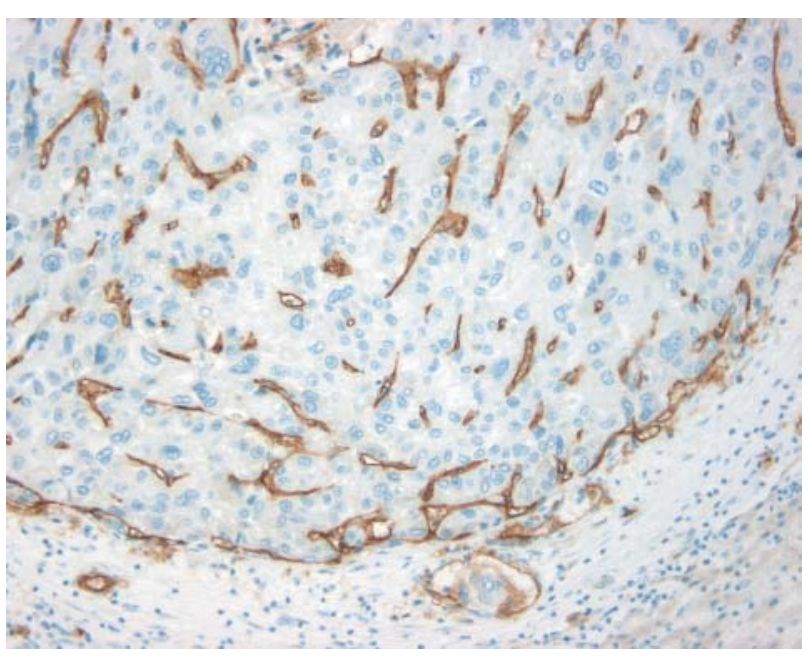

Figure 1 Area of hepatitis C virus related hepatocellular carcinoma showing high density of microvessels as assessed by anti-CD34 immunostaining. Original magnification, $\times 200$.

Child's class B, HCV infection, and tumour size (tables 3 and 4 ). The mean tumour MVD was 38 (SD, 8.9; range, 18-50) in the B-HCC group and 54 (SD, 13.8; range, 28-78) in the CHCC group. Differences were significant $(\mathrm{p}<0.01)$ (table 3$)$. The mean MVD was significantly higher in the C-HCC group when different Child's class disease and tumour size were taken into account (table 5).

In non-tumorous liver tissue, immunostaining for CD34 was sparse and more pronounced in the C-HCC group (mean MVD, 15; SD, 4.3; range, 3-24) than in the B-HCC group (mean MVD, 7; SD, 3.1; range, 0-12); differences were significant $(\mathrm{p}<0.01)$.

\section{DISCUSSION}

We found certain clinicopathological differences in relation to the aetiology of HCC. In accordance with previous reports, ${ }^{6-17}$ patients in the C-HCC group were significantly older than those with HBV infection. This is mainly thought to be the result of differences in the origin and duration of infection. ${ }^{9}$ HBV infection often occurs via perinatal transmission from the mother, whereas HCV infection is more often acquired in adulthood, via blood transfusions, intravenous drug use, or contaminated instruments. ${ }^{16} 39$

The average tumour diameter was significantly larger in the B-HCC group than in the C-HCC group. This finding is consistent with most studies, which show a higher incidence of more advanced cancers in patients with HBV infection

Table 3 Comparison between MVD and clinical features in the 100 hepatocellular carcinomas studied

\begin{tabular}{|c|c|c|c|}
\hline Variable & $\mathbf{N}$ & Mean (SD) MVD & p Value \\
\hline \multicolumn{4}{|l|}{ Mean age } \\
\hline$\leqslant 63.9$ & 57 & $46(7.6)$ & \multirow[t]{2}{*}{ NS } \\
\hline$>63.9$ & 43 & 51 (6.9) & \\
\hline \multicolumn{4}{|l|}{ Sex } \\
\hline Male & 82 & $49(10.2)$ & \multirow[t]{2}{*}{ NS } \\
\hline Female & 18 & $46(9.3)$ & \\
\hline \multicolumn{4}{|l|}{ Child's class } \\
\hline A & 65 & $39(7.1)$ & \multirow[t]{2}{*}{$<0.01$} \\
\hline$B$ & 35 & $55(8.8)$ & \\
\hline \multicolumn{4}{|l|}{ Hepatitis virus status } \\
\hline Hepatitis B positive & 50 & $38(8.9)$ & \multirow[t]{2}{*}{$<0.01$} \\
\hline Hepatitis $C$ positive & 50 & $54(13.8)$ & \\
\hline
\end{tabular}

Table 4 Comparison between MVD and pathological features in the 100 hepatocellular carcinomas studied

\begin{tabular}{|c|c|c|c|}
\hline Variable & $N$ & Mean (SD) MVD & p Value \\
\hline \multicolumn{4}{|l|}{ Tumour size } \\
\hline$\leqslant 2 \mathrm{~cm}$ & 8 & $35(5.6)$ & $<0.03$ \\
\hline $2,1-5 \mathrm{~cm}$ & 67 & $56(9.8)$ & \\
\hline$>5 \mathrm{~cm}$ & 25 & $46(10.4)$ & \\
\hline \multicolumn{4}{|l|}{ Architectural pattern } \\
\hline Trabecular & 71 & 45 (9.3) & NS \\
\hline Pseudoglandular & 19 & $44(8.8)$ & \\
\hline Compact & 8 & $46(5.8)$ & \\
\hline Clear cell & 2 & $48(2.0)$ & \\
\hline \multicolumn{4}{|l|}{ Edmondson grade } \\
\hline G1-G2 & 56 & $47(8.4)$ & NS \\
\hline G3-G4 & 44 & 44 (7.2) & \\
\hline \multicolumn{4}{|c|}{ Microsatellite formation } \\
\hline Absent & 84 & $46(6.8)$ & NS \\
\hline Present & 16 & $50(7.8)$ & \\
\hline \multicolumn{4}{|l|}{ Fibrous capsule } \\
\hline Absent & 88 & $44(8.1)$ & NS \\
\hline Present & 12 & $49(7.6)$ & \\
\hline \multicolumn{4}{|l|}{ Vessel involvement } \\
\hline Absent & 68 & $48(7.6)$ & NS \\
\hline Present & 32 & $43(8.2)$ & \\
\hline
\end{tabular}

than in those with HCV infection. ${ }^{11}{ }^{12}{ }^{14-16}$ This is probably because HCV infected patients are closely followed up for chronic liver dysfunction, whereas HBV positive patients are comparatively young, asymptomatic, and have blood test results within normal ranges, so they seldom undergo imaging examination.

Tumour microsatellite formation was significantly higher in the C-HCC group; most satellite nodules in the C-HCC group were thought to be of multifocal origin, whereas in the B-HCC group, satellite nodules were intrahepatic metastases. These data are in accordance with the results of Miyagawa et al. ${ }^{10}$

When all cases were considered, MVD was significantly higher in patients with advanced liver disease and in tumours of intermediate size. These findings are in accordance with those of El-Assal et al. ${ }^{22}$ A possible explanation for the relation between MVD and HCC size may be found in the characteristics of the tumour microcirculation, which change as the tumour grows. ${ }^{22}$ El-Assal et al have hypothesised that angiogenesis plays a fundamental role in the tumour proliferation of HCCs between 2 and $5 \mathrm{~cm}$ in diameter, whereas the importance of neovascularisation is reduced as the tumour becomes larger.

In our study, MVD was significantly higher in the C-HCC group, even when our cases were stratified according to tumour diameter and Child's class disease, thus suggesting a

Table 5 MVD in B-HCC and C-HCC in relation to Child's class and tumour diameter

\begin{tabular}{|c|c|c|c|}
\hline \multirow[b]{2}{*}{ Variable } & \multicolumn{2}{|c|}{ Mean (SD) MVD } & \multirow[b]{2}{*}{ p Value } \\
\hline & B-HCC & C-HCC & \\
\hline \multicolumn{4}{|l|}{ Child class } \\
\hline$A$ & $35(6.9)$ & $47(8.2)$ & $<0.03$ \\
\hline B & $48(8.4)$ & $59(9.8)$ & $<0.01$ \\
\hline \multicolumn{4}{|c|}{ Tumour diameter } \\
\hline$\leqslant 2 \mathrm{~cm}$ & $30(4.1)$ & $44(7.2)$ & $<0.04$ \\
\hline $2,1-5 \mathrm{~cm}$ & $45(9.3)$ & $62(11.2)$ & $<0.001$ \\
\hline$>5 \mathrm{~cm}$ & $41(8.2)$ & $54(9.8)$ & $<0.001$ \\
\hline
\end{tabular}

B-HCC, hepatitis B virus related hepatocellular carcinoma; C-HCC, hepatitis $C$ virus related hepatocellular carcinoma; MVD, microvessel density. 
particular link between angiogenesis and HCV infection. This result differs from the findings of previous studies. ${ }^{22} 27$ ElAssal et al failed to demonstrate a significant correlation between MVD and HCC associated with either HCV or HBV infection. Nevertheless, differences between MVD results in our study and the above mentioned one may be attributable to differences in the study designs, the study populations, and the different antibodies used to highlight microvessels; El-Assal et al used a factor VIII related antibody, whereas we used anti-CD34, which is highly sensitive and specific for labelling microvessels in HCCs. ${ }^{24} 278^{25-37}$ Nevertheless, no differences in MVD values in HBV and HCV related HCC were found by Tanigawa and colleagues ${ }^{27}$ or Yamamoto and colleagues $^{28}$ when angiogenesis was evaluated with antiCD34. A possible explanation may be found in the different characteristics of the study populations, especially in relation to the number of $\mathrm{HBV}$ and HCV infected patients and the clinicopathological features of each series. Interestingly, Yamamoto et al found a significantly higher MVD in the surrounding non-neoplastic tissue of C-HCCs compared with the surrounding liver of the patients with B-HCC. This last observation is consistent with our results. Moreover, Yamamoto et al reported significantly higher expression of platelet derived endothelial cell growth factor (PD-ECGF), a well known angiogenic factor, in C-HCC compared with BHCC, whereas no differences were found in the surrounding tissue. PD-ECGF expression was found to correlate with MVD in the surrounding liver tissue but not within HCC. From these data the authors speculated that PD-ECGF may play a role in the angiogenesis of the surrounding liver but not in HCC; nevertheless, they emphasise that there may be cooperation between HCV and PD-ECGF in hepatocarcinogenesis mediated by the angiogenic pathway.

\section{"Microvessel density was significantly higher in the hepatitis C virus (HCV) related hepatocellular carcinoma group, even when our cases were stratified according to tumour diameter and Child's class disease, thus suggest- ing a particular link between angiogenesis and HCV infection"}

A recent study by Rahman et al also found that angiogenesis was particularly important in HCV associated HCC. ${ }^{30}$ The authors found that inducible nitric oxide synthase (iNOS) expression was significantly higher only in the hepatitis C virus positive HCCs and significant correlations between iNOS, cyclooxygenase-2 (COX-2) and MVD were also found in the same tumour group. Therefore, the upregulation of iNOS and the induction of COX-2 expression may play a role in tumour angiogenesis in C-HCCs.

There is some evidence that other angiogenic factors, such as vascular endothelial growth factor, angiopoietins, and tissue factor, may play an important role in the development and progression of $\mathrm{HCC}^{40-42}$; however, to date little is known about the relation between HCV infection and the regulatory mechanisms of angiogenesis in human HCC.

In conclusion, our results highlight the fact that the clinicopathological profiles of B-HCC and C-HCC may differ. C-HCCs were found to present as smaller tumours in older patients, with a higher incidence of tumour microsatellite formation, thus indicating differences in the tumorigenic potential of HBV and HCV infection. Furthermore, we found higher MVD values in both the HCCs and the surrounding liver tissue of HCV positive cases, suggesting that angiogenesis may be especially linked to HCV infection, and may play a more important role in tumour progression in C-HCC than in B-HCC. Further research in this direction may help to elucidate the role of HCV in the induction of angiogenesis in
Take home messages

- Hepatitis C virus (HCV) related hepatocellular carcinomas (C-HCCs) present as smaller tumours in older patients, with a higher incidence of tumour microsatellite formation and higher microvessel density values both in the tumorous and non-tumorous areas

- These findings suggest a link between HCV infection, angiogenesis, and hepatocarcinogenesis

- Further research may help to elucidate the role of HCV in the induction of angiogenesis in $\mathrm{HCC}$ and may form the basis for future novel therapeutic strategies

HCC and may form the basis for future novel therapeutic strategies.

\section{Authors' affiliations}

L Messerini, L Novelli, C E Comin, Department of Human Pathology and Oncology, University of Florence Medical School, Viale G.B. Morgagni, 85, 50134 Florence, Italy

\section{REFERENCES}

1 Kim CM, Koike K, Saito I, et al. HBx gene of hepatitis B virus induces liver cancer in transgenic mice. Nature 1991;351:317-20.

2 Trevisani F, D'Intino PE, Caraceini P, et al. Etiologic factors and clinical presentation of hepatocellular carcinoma. Differences between cirrhotic and noncirrhotic Italian patients. Cancer 1995;75:2220-32.

3 Salvucci M, Lemoine A, Saffroy R, et al. Microsatellite instability in European hepatocellular carcinoma. Oncogene 1999;18:181-7.

4 Moriya K, Fujie $\mathrm{H}$, Shintani $Y$, et al. The core protein of hepatitis $\mathrm{C}$ virus induces hepatocellular carcinoma in transgenic mice. Nat Med 1998:4:1065-7.

5 Dutta U, Kench J, Byth $\mathrm{H}$, et al. Hepatocellular proliferation and development of hepatocellular carcinoma: a case control study in chronic hepatitis C. Hum Pathol 1998;29:1279-84.

6 Lee HS, Han JC, Kim CY. Predominant etiologic association of hepatitis $\mathrm{C}$ virus with hepatocellular carcinoma compared with hepatitis $B$ virus in elderly patients in a hepatitis-B endemic area. Cancer 1993;72:2564-7.

7 Takenaka K, Yamamoto K, Taketomi A, et al. A comparison of the surgical results in patients with hepatitis $B$ versus hepatitis $C$-related hepatocellular carcinoma. Hepatology 1995;22:20-4

8 Takano S, Yokosuka O, Imazeki F, et al. Incidence of hepatocellular carcinoma in chronic hepatitis B and C: a prospective study of 251 patients. Hepatology 1995;21:650-5.

9 Shiratori $Y$, Shiina S, Imamura $M$, et al. Characteristic difference of hepatocellular carcinoma between hepatitis $B$ and $C$ viral infection in Japan. Hepatology 1995;22:1027-33

10 Miyagawa S, Kawasaki S, Makuuchi M. Comparison of the characteristics of hepatocellular carcinoma between hepatitis $B$ and $C$ viral infection: tumour multicentricity in cirrhotic liver with hepatitis C. Hepatology 1996;24:307-10.

11 Yamanaka N, Tanaka T, Tanaka W, et al. Correlation of hepatitis virus serologic status with clinicopathological features in patients undergoing hepatectomy for hepatocellular carcinoma. Cancer 1997;79:1509-15.

12 Shuto T, Hirohashi K, Kubo S, et al. Differences of resected hepatocellular carcinoma with hepatitis B or C virus. Hepatogastroenterology 1998:45: 1722-5

13 Stroffolini T, Andreone P, Andriulli A, et al. Characteristic of hepatocellular carcinoma in Italy. J Hepatol 1998;29:944-52.

14 Tanabe G, Nuruki K, Baba Y, et al. A comparison of hepatocellular carcinoma associated with $\mathrm{HBV}$ or $\mathrm{HCV}$ infection. Hepatogastroenterology 1999;46:2442-6

15 Benvegnù L, Alberti A. Patterns of hepatocellular carcinoma development in hepatitis $B$ virus and hepatitis $C$ virus related cirrhosis. Antiviral Res 2001;52:199-207.

16 Gelatti U, Donato F, Tagger A, et al. Etiology of hepatocellular carcinoma influences clinical and pathological features but not patient survival. Am J Gastroenterol 2003;98:907-14.

17 Wakai T, Shirai Y, Yokoyama N, et al. Hepatitis viral status affects the pattern of intrahepatic recurrence after resection for hepatocellular carcinoma. Eur J Surg Oncol 2003;29:266-71.

18 Folkman J. What is the evidence that fumours are angiogenesis dependent? $J$ Natl Cancer Inst 1990;82:4-6.

19 Liotta LA, Steeg PS, Stetler-Stevenson WG. Cancer metastasis and angiogenesis: an imbalance of positive and negative regulation. Cell $1991 ; 64: 327-36$ 
20 Folkman J. Angiogenesis in cancer, vascular, rheumatoid and other disease Nat Med 1995; 1:27-31.

21 Hanahan D, Folkman J. Patterns and emerging mechanisms of the angiogenic switch during tumorigenesis. Cell 1996;86:353-64.

22 El-Assal ON, Yamanoi A, Soda Y, et al. Clinical significance of microvessel density and vascular endothelial growth factor expression in hepatocellular carcinoma and surrounding liver: possible involvement of vascular endothelial growth factor in the angiogenesis of cirrhotic liver. Hepatology 1998;27:1554-62.

$23 \mathrm{Ng}$ IO, Poon RT, Lee JMF, et al. Microvessel density, vascular endothelial growth factor and its receptors Flt- 1 and Flk-1/KDR in hepatocellular carcinoma. Am J Clin Pathol 2001;116:838-45.

24 Poon RT, Ng IO, Lau C, et al. Tumour microvessel density as a predictor of recurrence after resection of hepatocellular carcinoma: a prospective study. J Clin Oncol 2002;20:1775-85.

25 Park YN, Yang CP, Fernandez GJ, et al. Neoangiogenesis and sinusoidal "capillarization" in dysplastic nodules of the liver. Am J Surg Pathol 1998;22:656-62

26 Park YN, Kim YB, Yang KM, et al. Increased expression of vascular endothelial growth factor and angiogenesis in the early stage of multistep hepatocarcinogenesis. Arch Pathol Lab Med 2000;124:1061-5.

27 Tanigawa N, Lu C, Mitsui T, et al. Quantitation of sinusoid-like vessels in hepatocellular carcinoma: its clinical and prognostic significance. Hepatology 1997;26:1216-23.

28 Yamamoto A, Dhar DK, El-Assal N, et al. Thymidine phosphorylase (plateletderived endothelial cell growth factor), microvessel density and clinical outcome in hepatocellular carcinoma. J Hepatol 1998;29:290-9.

29 Mazzanti R, Messerini L, Monsacchi L, et al. Chronic viral hepatitis induced by hepatitis $C$ but not hepatitis $B$ virus infection correlates with increased liver angiogenesis. Hepatology 1997;25:229-34.

30 Rahman MA, Dhar DK, Yamaguchi E, et al. Coexpression of inducible nitric oxide synthase and COX-2 in hepatocellular carcinoma and surrounding liver: possible involvement of COX-2 in the angiogenesis of hepatitis $\mathrm{C}$ viruspositive cases. Clin Cancer Res 2001;7:1325-32.
31 Tsuda $\mathrm{H}$, Oda $T$, Sakamoto $M$, et al. Different pattern of chromosomal allele loss in multiple hepatocellular carcinomas as evidence of their multifocal origin. Cancer Res 1992;52:1504-9

32 Kumada T, Nakano S, Takeda I, et al. Patterns of recurrence after initial treatment in patients with small hepatocellular carcinoma. Hepatology 1997:25:87-92

33 Hamilton SR, Aaltonen LA. Tumours of the liver and intrahepatic bile ducts. In:Pathology and genetics. Tumours of the digestive system. World Health Organisation classification of tumours. Lyon: IARC Press, 2000:157-202.

34 Edmondson HA, Steiner PE. Primary carcinoma of the liver: a study of 100 cases among 48,900 necropsies. Cancer 1954;7:462-503.

35 Anthony PP, Ramani P. Endothelial markers in malignant vascular tumours of the liver: superiority of QB-END/10 over Von Willebrand factor and Ulex europaeus agglutinin 1. J Clin Pathol 1991;44:29-32.

36 Ruck P, Xiao JC, Kaiserling E. Immunoreactivity of sinusoids in hepatocellular carcinoma. An immunohistochemical study using lectin UEA-1 and antibodies against endothelial markers, including CD34. Arch Pathol Lab Med 1995: 119:173-8

37 Maeda T, Adachi E, Kaijyama K, et al. CD34 expression in endothelial cells of small hepatocellular carcinoma: its correlation with tumour progression and angiographic findings. J Gastroenterol Hepatol 1995; 10:650-4.

38 Weidner N, Semple JP, Welch WR, et al. Tumour angiogenesis and metastasis: correlation in invasive breast cancer. N Engl J Med $1991 ; 324: 1-8$.

39 Lauer GM, Walker B. Hepatitis C virus infection. N Engl J Med 2001;345:41-52

40 Mitsuhashi N, Shimizu H, Ohtsuka M, et al. Angiopoietins and Tie-2 expression in angiogenesis and proliferation of human hepatocellular carcinoma. Hepatology 2003:37:1105-13.

41 Moon WS, Rhyu KH, Kang MJ, et al. Overexpression of VEGF and angiopoietin 2: a key to high vascularity of hepatocellular carcinoma? Mod Pathol 2003;16:552-7.

42 Poon RT, Lau CP, Ho JW, et al. Tissue factor expression correlates with tumour angiogenesis and invasiveness in human hepatocellular carcinoma. Clin Cancer Res 2003;9:5339-45. 